\title{
Improving the environmental assessment of objects in the system of construction engineering
}

\author{
Vadim Bespalov ${ }^{1}$ and Ekaterina Kotlyarova ${ }^{1, *}$ \\ ${ }^{1}$ Don State Technical University, 162, Socialisticheskaya Str., 344022, Rostov-on-Don, Russia
}

\begin{abstract}
The problem of maintaining the proper level of environmental safety in urban areas currently is not yet fully resolved. In this case, a special role at the level of impact on the environment is played by the industry of design, construction and operation of construction projects and urban facilities for various purposes. To solve this issue in our research, we identified and systematized the main characteristics of the groups, which largely determine the state of both individual objects of the urban environment and urban economy, and urbanized territories as a whole. As a result, groups of environmental, economic and social characteristics were obtained. In addition, we paid attention to the distribution of the importance of the evaluation criteria regarding the type of functional zone of the urbanized territory. Further in the article, we proposed to determine the environmental criteria based on the characteristics of the state of individual components of the surrounding urban environment and the characteristics of economic activity in the territory under consideration, causing qualitative changes in the state of this environment. Our research allows us to identify the dominant importance of the environmental criteria for a specific urbanized area and the need to take it into account at the initial design stage. At further stages, we intend to conduct scientific research to derive a dimensionless indicator based on the environmental criteria described above with the further development of an appropriate methodology, which will allow us to assess comprehensively the degree of construction projects and urban facilities for various purposes impact on the environmental safety of urbanized territories and develop appropriate measures for its optimization and reduction.
\end{abstract}

\section{Introduction}

The problems of preserving the natural framework and environmental safety of territories subject to continuous anthropogenic impact, as well as the health of residents and the quality of their livelihoods are extremely urgent at the present time [1]. The effects of technogenic factors are most seen in large settlements due to the dense concentration of engineering systems, as well as construction and urban facilities in as a rule a compact area.

\footnotetext{
* Corresponding author: ekkot.arch@gmail.com
} 
A special role in the level of negative environmental impact of urbanized territories is played by the design, construction and operation of various construction and urban facilities, despite the fact that the formation of cities' infrastructure and rural settlements in accordance with the principles of sustainable development is an actual global trend in urban planning. It is also important to note that at present the main attention of specialists is aimed at maximizing the quality of the urban environment in the structure of existing builtup territories, but not at the development of new spaces for life. This is due, among other things, to the fact that the extensive development way of large cities loses its stimulating significance, and accordingly, the intensive use of already developed and well-maintained territories comes to the fore [2].

The important factors are also changes in urban infrastructure, consisting in continuous urbanization and, accordingly, the transformation of the use of certain functional areas in the urban environment due to its spatial expansion. This can be seen when comparing the master plans of large cities 20-30 years ago and the present: many areas reserved for industry were moved outside the city, and territories and sometimes buildings of their former location were actively rebuilt for large cultural and leisure facilities, shopping and entertainment centers, offices or even sometimes loft-type housing.

In our opinion, the design stage is an extremely important stage in the life cycle of any construction project and city economy. It is in the process of its implementation that the maximum number of scientifically justified and environmentally justified solutions can be considered. To do this, we can collect the necessary information, perform a competent analysis of the projected negative impact of the object on the environmental safety of urban areas and propose appropriate measures in design decisions. This concerns not only the section "Environmental Protection Activities", but also the part devoted to the planning of the land plot, as well as to architectural and engineering solutions.

The analysis of the well-known methodological approaches to assessing the state of the urbanized territories environment [3] allows us to conclude that a comprehensive assessment requires taking into account social, environmental, economic conditions and a number of limitations that have not yet been fully developed in modern studies. This can be explained by the fact that the theory of sustainable development of urbanized territories, being very large-scale and relevant, is still in the stage of improvement. Thus, one of the main stages of further research in the direction under consideration should be the improvement of the assessment of construction projects and households for various purposes, primarily from an environmental point of view with maintaining or minimizing the impact on the rate of economic growth in urban areas. It is the positive impact on the environmental characteristics of the territories that we consider to be dominant in the theory of sustainable development.

\section{Materials and Methods}

Currently, professional, political and public organizations are paying more and more attention to the discussion of the problem of environmental pollution by construction objects and urban facilities for various purposes. That is why one of the urgent areas is the application of the set of actions from the environmental and construction engineering systems aimed at creating new capital construction projects and rebuilding existing ones using the best available technologies. In order for the environmental engineering system to implement the concept of sustainable development of the construction object and city facilities for various purposes, it is necessary to carry out environmental adjustment of the indicators of sustainable development and economic progress of urbanized territories. Subsequent implementation of the adjusted criteria into the appropriate methodology will allow optimizing the operation of facilities for various purposes, both in the direction of 
reducing the harmful effects on the environment, and for further improving the efficiency of processes at all stages of their life cycle.

To achieve the goals set in our research, we consider it is necessary to identify and systematize into groups the main characteristics that largely determine the state of both individual objects of the urban environment and urban economy, and urbanized territories as a whole.

In our opinion, there can be three main groups of characteristics, namely environmental, economic, and social, this is due to environmental degradation of urbanized areas that causes significant harm to people's health, the quality of their livelihoods, and also inhibits economic development [4, 5]. That is why, in our research, in addition to basic environmental ones, we also suggest taking into account:

- economic characteristics, which include: tax revenues, as well as payments, deductions and other payments to the local (city) budget; investment commitments aimed at the development of the social sphere and economic development of the considered urban area; rent of real estate, land; economic damage from pollution of the urban environment;

- social characteristics that can be divided into two large groups. On the one hand, they include such parameters as the infrastructure of the urban territory and its planning; the degree of comfort of the living conditions of the population in the territory under consideration; the degree of improvement of the territory under consideration; creation and availability of public goods as a result of the functioning of natural resources in the territory under consideration (squares, parks, water bodies, etc.); the presence of social facilities in the territory under consideration. On the other hand, the social characteristics include demographic and health, which can include, in its turn: the number of people (population) living in the urban area under consideration; population density; the incidence rate of the adult and children's population; mortality of adults and children; medical and hygienic abnormalities; oncological and other specific, including autoimmune diseases; impaired reproductive function among women; life expectancy; physical and mental development of children; genetic disorders.

Let us consider in more detail each of these groups of characteristics.

Economic characteristics, on the one hand, determine the benefits and the effect of operating anthropogenic facilities located on the considered built-up territory, allowing an analysis of the financial potential of the territory, and, on the other hand, assess the losses in the economy caused by pollution of the urban environment.

To assess the economic damage by the objects of urban infrastructure and urban economy, it is reasonable to use the concept of individual environmental human risk proposed in. Moreover, the total probability of the negative impact of various risk factors can be highlighted as the main assessment. Thus, for each construction project or urban economy that creates environmental risk in the territory under consideration, firstly it is necessary to determine the factors of the negative impact on the surrounding urban environment (polluting substances and physical fields), and then the sources of these factors.

The environmental risk of the population living in the territory adjacent to the areas of the construction and urban facilities for various purposes, including the construction of transport and engineering infrastructure, and subject to constant negative impact, is the basis for drawing up territory comfort maps.

The social characteristics of both groups must be taken into account, first of all, in order to ensure sustainable development of industrial zones of urbanized territories, as well as to assess the quality of living conditions based on the calculation of social criteria [6]. It is industrial zones that have a negative impact on the state of the urban environment, causing a tense ecological situation, which causes a decrease in the degree of comfort of life due to 
a violation of the natural conditions of life, and, therefore, leads to a threat to human health in the territory under consideration, which is the main indicator of social well-being.

Demographic and health characteristics included in the list of social ones should be used in assessing the negative impact of increased levels of material and physical pollution of the urban environment on the health of people in the urban area under consideration. Numerous scientific studies have shown that in an unfavorable environmental situation, the number of diseases increases sharply in people, especially among children, and mortality also increases. In conditions of worsening public health, the requirements for organizing and managing a set of measures, processes and phenomena aimed at ensuring the environmental safety of urban areas are increasing significantly.

In further research to assess the demographic and health characteristics of the analyzed urban area, we suggest taking into account: indicators of changes in any type of pathology; indicators of physical development; indicators of mental development; features of the aging process and mortality rates taking into account the main types of diseases and forms of morbidity caused by negative environmental conditions. Since many environmental, economic, social, and other factors affect the state of health of a population, this certainly causes certain difficulties in establishing the role and degree of impact of each factor.

This idea is the basis for monitoring public health in the general system of sociohygienic monitoring, which we consider as the main tool for assessing the state of public health and identifying environmental factors that determine its formation. At the same time, an important integral indicator recommended by the World Health Organization (WHO) as a criteria for assessing the health status and standard of living of a population in any region is the average life expectancy of a population.

Social characteristics, including the demographic and health-related ones, are also the basis for determining environmental risk for the population, indicators of environmental safety of the population [7], an integrated assessment of the state of the urban environment, dependencies morbidity of the population on the level of pollution of the urban environment. So, in [2-4], an approach was proposed to determine a comprehensive assessment of the state of the urban environment, based on the relationship between the parameters of the state of the environment and the indicator of public health.

As for the most important, from our point of view, group of environmental factors characterizing construction projects and urban facilities for various purposes, we proposed to include the following factors, which are graphically presented in Fig. 1:

- the objects' location in the territory under consideration (buildings and structures) of residential, industrial, infrastructural and recreational zones, not only relative to each other, but also relative to the main natural objects located in this territory (for example, water bodies, various types of plant objects, specially protected territories and etc.);

- types and level of negative impact of the considered objects on the environment of urbanized territories;

- quality condition of the main environmental components of urban areas (air basin, water bodies, soil cover).

At the same time, it is advisable to base an assessment of the air condition of the considered urbanized territory in accordance with applicable law on:

- identification of the main sources of air pollution;

- classification of sources according to their contribution to air pollution and according to the sequence of planned environmental protection measures;

- determination of air pollution levels by appropriate sources;

- calculation of fields of maximum single and average daily concentrations of pollutants from the totality of identified sources of air pollution;

- identification of areas with excess concentrations of pollutants; 
- zoning of the territory under consideration according to the values of the total hygienic criteria for air pollution.

Moreover, to determine the concentrations of pollutants created by emissions of various technogenic sources, it is advisable to use the following methods [3]:

- an instrumental method based on the use of automatic gas analyzers that continuously measure the concentration of pollutants in emissions of anthropogenic sources, usually used to control the main or most common types of pollutants;

- instrumental laboratory method, involving the sampling of exhaust gases directly at the source of pollutants, followed by their laboratory chemical analysis;

- indicator method, based on the use for rapid analysis and preliminary assessment of the concentration of pollutants of indicator elements that change color depending on the concentration of pollutants in the sampled gas;

- calculation method based on the determination of mass emissions of pollutants according to information on the composition of the feedstock and fuel in the process under consideration;

- a method for controlling emissions according to the analysis of actual atmospheric pollution, based on determining the actual value of the concentration of pollutants by emissions of the considered sources outside them, followed by comparison with the reference concentration of the corresponding pollutants, taking into account the direction and speed of the wind.

Assessment of the state of water bodies in the considered territory of urban development is determined on the basis of [3]:

- sanitary and hygienic characteristics of the studied water bodies;

- water management characteristics of the territory under consideration;

- characteristics of the main sources of pollution of surface water bodies.

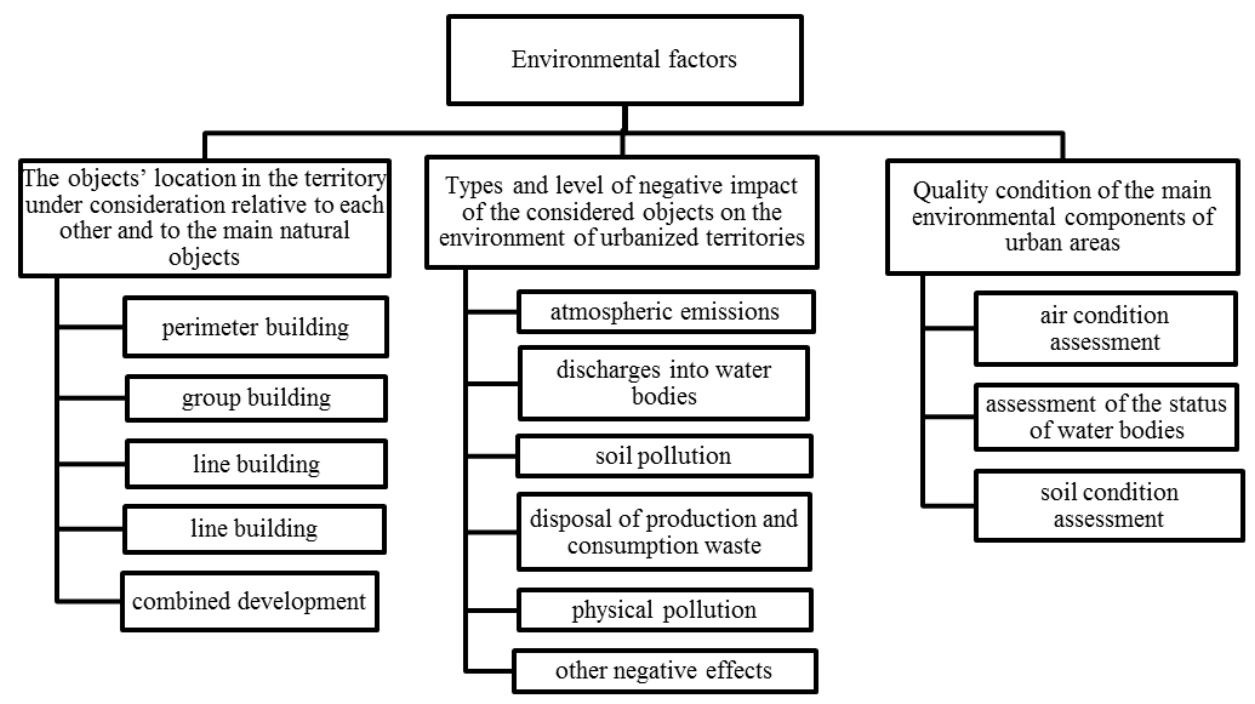

Fig. 1. Environmental factors characterizing the construction and urban facilities for various purposes.

At the same time, it is advisable to organize control points, first of all, in water bodies and watercourses that are of great economic importance for the territory under consideration, as well as which are subject to significant pollution by industrial, domestic, and agricultural wastewaters.

Assessment of the condition of the soil cover is based on the determination of: 
- the level of soil pollution and the characteristics of the total concentration of chemical elements in soils;

- characteristics of the degree of disturbance (degradation) of the soil cover.

Assessment of physical factors of influence (noise, vibration, electromagnetic and ionizing radiation) is based on the definition [7]:

- the main sources of negative impact and their intensity;

- territorial areas of discomfort, in which there is an excess of the permissible level of negative impact of physical factors.

The listed environmental parameters are an integral element of a factorial assessment of the state of the urban environment.

To the group of natural and recreational factors and parameters we have assigned:

- the main characteristics of natural and recreational resources (parks, gardens, squares, boulevards, intra-quarter landscaping, etc.);

- the degree of rational use of available natural and recreational resources;

- functional value of lands occupied by natural and recreational resources.

From the standpoint of ensuring the ecological safety of the urban environment, natural and recreational objects (resources) perform three main functions: providing natural resources; assimilation of waste and pollution; providing people with natural services, such as recreation, aesthetic pleasure and a number of others. These functions can also be represented as components of one general function of the environment - the function of lifehood.

The need to take into account the parameters of the functional value of land consists of the fact that the land resources planned for withdrawal for construction can be used in agriculture and produce products, which can make it advisable to change investment projects in the direction of increasing the cost of the construction object itself due to its maximum concentration, as well as additional costs to attract unsuitable and inconvenient lands.

Natural and recreational resources include recreational landscapes, bioclimat, hydromineral resources. An imperative for the suitability of natural recreational resources is a favorable state of the environment.

In some works [8], only two main aspects were considered: integrated monitoring of urban lands and multicriteria assessment of the ecological state of urban areas. This consideration is limited to assessing the influence of technogenic factors on nature, which means that only the natural factor can be used. And for environmental assessment, in our opinion, it is necessary to have parameters of soil fertility, water-air regime of soil cover and soil pollution with pollutants.

In practice, various methods for assessing natural and recreational resources are known. The most common and to the maximum extent consistent with the general analysis of the recreational properties of the considered urban area is the assessment of the degree of favorable landscape, bioclimatic and environmental aspects for subsequent recreational use.

\section{Results}

An important role at the initial stage of improving the criteria-based assessment of construction and urban facilities for various purposes in the environmental and construction engineering system is played by the functional zoning of the urbanized territory [9-11], which consists in the allocation of targeted territorial zones based on the analysis of socioeconomic and environmental conditions architectural and planning structure of the territory under consideration, its economic relations and the main features of its directions Sounds. In other words, these are parts of the built-up territory, united by the dominant features of functional use and spatial organization, for which, for the purpose of territorial planning, 
the directions of structural transformations, types of development, the prevailing functional purpose and other characteristics are determined.

In accordance with generally accepted signs, as well as taking into account changes in the modern infrastructure of the urbanized territory, we propose to allocate the following zones according to their functional purpose in any investigated built-up territory:

- production (industrial buildings, structures, workshops and plots, industrial and storage areas, etc.);

- residential (residential buildings of various types: multi-apartment, cottage, etc.);

- recreational (squares, parks, gardens, embankments, beaches, sports grounds, buildings and structures, etc.);

- social (shopping and entertainment centers, catering facilities, dispensaries, psychological and physical rehabilitation centers, medical facilities, etc.) .;

- zone of engineering and transport infrastructure (objects, structures and communications of engineering infrastructure, transport hubs, street-road network of federal, regional and local significance, etc.).

Depending on the type of functional zone of the urbanized area under consideration, the priorities of the three main evaluation criteria described above are distributed differently (see Fig. 2.).
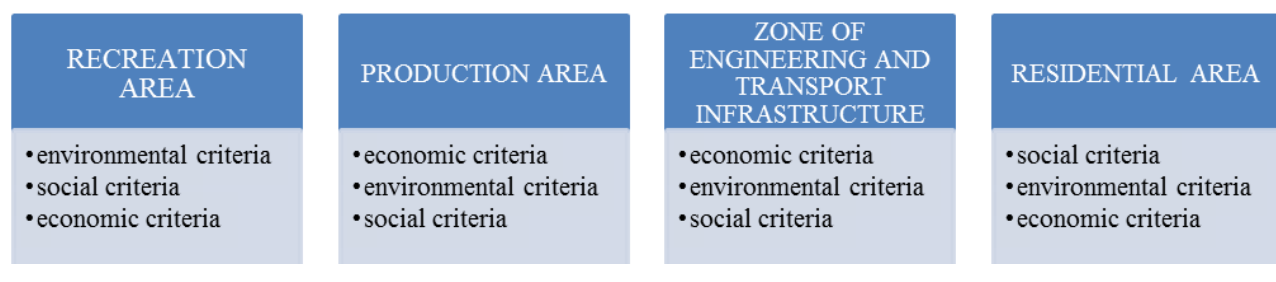

Fig. 2. Distribution of significant evaluation criteria depending on the functional area of the urban area.

So, for the territory of the recreational zone, which primarily performs the most important environmental, sanitary, protective, health-improving and landscape-forming functions, the environmental criteria should be the main one, then it is important to pay attention to the social criteria and, in the last turn, it is necessary to take into account the economic criteria.

And for the territories of production zones, as well as engineering and transport infrastructure, the main, of course, is the economic criteria, after which the environmental one is taken into account, and, lastly, the social criteria can be taken into account.

At the same time, the social criteria should be the main one for the territory of the residential zone, and after this it is necessary to take into account the environmental criteria and, last but not least, it is important to pay attention to the economic criteria.

As the main parameters that determine the state of the environment of urbanized territories, we used:

- volumes of air emissions, discharges into water bodies and waste generated;

- actual values of the levels of pollution of the urban environment (concentration of pollutants in the air, in water sources, in the soil), levels of pollution by physical fields (noise, vibration, electromagnetic and ionizing radiation).

Having studied separately the groups of factors that make up the ecological, economic, and social characteristics of the environment of urbanized territories, we have come to the conclusion that at present the leading in importance position is occupied by environmental characteristics. This decision is confirmed by the global trend voiced in the «Global Risks Report» at the World Economic Forum in Davos in January 2020, where for the first time in 15 years of the publication of the report, the five most likely risks in a ten-year perspective were environmental ones. Accordingly, it is likely that in assessing the state of 
the environment not only recreational, but also industrial, residential, as well as engineering and transport infrastructure zones, the significance of the environmental criterion, instead of second or third positions, will increase to a leading or equivalent position.

When calculating the environmental criterion, we propose combining in one formula the values of the actual and the threshold limit value of pollutants in the soil, water bodies, air basin, as well as the effects of physical fields.

Thus, the ecological criterion of $\mathrm{C}_{\text {ecolog }}$ of the study area, taking into account the parameters of pollution of the atmosphere, water, soil and pollution created by physical fields, can be determined by the following formula:

$$
C_{\text {ecolog }}=\left(\sum_{i=1}^{n} \frac{C_{i}^{\text {atm }}}{T V L_{i}^{\text {atm }}}+1\right)^{W_{3}^{\text {atm }}} \cdot\left(\sum_{i=1}^{n} \frac{C_{i}^{\text {water }}}{T V L_{i}^{\text {water }}}+1\right)^{W_{3}^{\text {water }}} \cdot\left(\sum_{i=1}^{n} \frac{C_{i}^{\text {soil }}}{T V L_{i}^{\text {soil }}}+1\right)^{W_{3}^{\text {soil }}} \cdot\left(\sum_{i=1}^{4} \frac{L_{i}}{P E L_{i}}+1\right)^{W_{3}^{\text {energ }}}-1
$$

where $\mathrm{C}_{\mathrm{i}}{ }^{\text {atm }}$ - concentration of pollutants in the atmosphere, $\mathrm{mg} / \mathrm{m} 3 ; \mathrm{C}_{\mathrm{i}}^{\text {water }}$ - concentration of pollutants in water, $\mathrm{mg} / \mathrm{m} 3 ; \mathrm{C}_{\mathrm{i}}^{\text {soil }}$-the concentration of pollutants in the soil, $\mathrm{mg} / \mathrm{kg}$; TLV - the threshold limit value of pollutants in the corresponding component of the environment, $\mathrm{mg} / \mathrm{m} 3, \mathrm{mg} / \mathrm{kg} ; \mathrm{L}_{\mathrm{i}}$ - noise levels, $\mathrm{dBA}$; vibration, dBA; electromagnetic, $\mathrm{V}$ $/ \mathrm{m}$ and ionizing radiation, $\mu \mathrm{R} / \mathrm{h}$; PEL - permissible exposure limit of a physical field, $\mathrm{dBA}, \mathrm{V} / \mathrm{m}, \mu \mathrm{R} / \mathrm{h} ; \mathrm{W}_{3}{ }^{\mathrm{j}}$ is the weight coefficient of the environment component (atmosphere, water, soil, physical field).

Thus, the $\mathrm{C}_{\text {ecolog }}$ ecological criteria for assessing the state of the environmental components of urbanized territories is determined by us on the basis of the characteristics of the state of individual components of the urban environment and the characteristics of economic activity in the territory under consideration, causing qualitative changes in the state of this environment.

\section{Discussion}

As a result of the research phase, we examined and analyzed the groups of factors that make up the ecological, economic and social environmental characteristics of urbanized territories, which are currently used to assess the individual components of the environmental safety of urbanized areas. It is these characteristics that are advisable to use in the environmental adjustment of the indicators of sustainable development and economic progress of urbanized territories, as well as for the subsequent formation of a methodology for a comprehensive assessment of the environmental safety of urban areas based on data on the pollution of individual components of the urban environment (atmosphere, water bodies, soil and vegetation cover) pollutants and physical fields.

However, such an integrated approach to assessing the environmental safety of urban areas, assuming a simultaneous solution of environmental, sanitary, hygienic, technical, organizational, social, economic and other tasks, in our opinion, should also take into account data on the impact of environmental pollution of the urban environment and the improvement of the urban area under consideration on socio-demographic characteristics, as well as on the economic condition of the study area.

\section{Conclusions}

Our studies allow us to identify the paramount importance of the environmental criterion for a specific urbanized area and the need to take it into account at the initial design stage.

At further stages, we intend to conduct scientific research to derive a dimensionless indicator based on the above environmental criterion with the subsequent development of 
an appropriate methodology, which will allow us to comprehensively assess the degree of impact of construction projects and urban facilities for various purposes on the environmental safety of urbanized territories and develop appropriate measures for its optimization and reduction.

\section{References}

1. R.T.T. Forman, J. Wu, Nature 537, 608-611 (2016) doi: 10.1038/537608a

2. V. Bespalov, E. Kotlyarova, E3S Web of Conferences, EDP Sciences, 00060 (2019) doi: $10.1051 / \mathrm{e} 3$ sconf $/ 201912600060$

3. V. Bespalov, E. Kotlyarova, Iop Conference Series: Earth and Environmental Science, 012036 (2018) doi: 10.1088/1755-1315/177/1/012036

4. V. Bespalov, E. Kotlyarova, Matec Web of Conferences, EDP Sciences, 05005 (2017) doi: $10.1051 /$ matecconf $/ 201712905005$

5. M. Smith, Greening the Built Environment, Earthscn from Routledge (2013)

6. S. Deshkar, V. Adane, Urban Disasters and Resilience in Asia, 245-267 (2016) doi: 10.1016/B978-0-12-802169-9.00016-1

7. S. Sheina, A. Fedorovskaya, Matec Web of Conferences, EDP Sciences, 07010 (2017) doi: $10.1051 /$ matecconf $/ 201710607010$

8. V. Ilyichev, S. Emelyanov, V. Kolchunov, N. Bakayeva, S. Kobeleva, Procedia Engineering 117, 126-131 (2015) doi: 10.1016/j.proeng.2015.08.133

9. V.M. Jayasooriya, A.W.M. Ng, S. Muthukumaran, S. Perera, Urban Forestry \& Urban Greening 21, 34-47 (2017) doi: 10.1016/j.ufug.2016.11.007

10. R.G.G. Caiado, D.R. Freitas, L.V. Mattenvironment, O.L.G. Quelhas, W.L. Filho, Journal of Cleaner Production 165, 890-904 (2017) doi: 10.1016/j.jclepro.2017.07.166

11. S. Sheina, A. Fedorovskaya, Matec Web of Conferences, EDP Sciences, 01012 (2018) doi: 10.1051/matecconf/201819604004

12. D.A. Gura, Y.V. Dubenko, G.G. Shevchenko, E.E. Dyshkant, N.I. Khusht, Lecture Notes in Civil Engineering book series 50, 185-190 (2020). DOI: 10.1007/978-98115-0454-9_19

13. D. Gura, M. Kuzyakina, I. Gribkova, IOP Conference Series: Earth and Environmental Science 403(1), 012176 (2019). DOI: 10.1088/1755-1315/403/1/012176

14. S.A. Isaev, P.A. Baranov, N.I. Vatin, Y.V. Zhukova, A.G. Sudakov. Technical Physics Letters. 2014. 40(8). Pp. 653-656. DOI:10.1134/S1063785014080057.

15. Z. Jakšic, D. Ladjinović, M. Trivunić, N. Harmati, N. Vatin. Procedia Engineering. 2015. 117(1). Pp. 502-515. DOI:10.1016/j.proeng.2015.08.252 